\title{
Energy balance-related factors associating with adolescent weight loss intent: evidence from the 2017 National Youth Risk Behavior Survey
}

\author{
Ryan D. Burns (D
}

\begin{abstract}
Background: The purpose of this study was to examine specific energy balance-related behaviors (sedentary behaviors, physical activity, and dietary) associating with adolescent weight loss intent using data from the 2017 US Youth Risk Behavior Survey (YRBS).

Methods: This was a cross-sectional study that employed a multi-stage cluster sampling procedure to obtain a representative sample of US adolescents. The target population consisted of public and private high schoolers from grades 9 through 12. The number of sampled adolescents was 18,324 with 14,765 of the 18,324 sampled students (Mean age $=15.9$ (1.3) years) submitting questionnaires with usable data (81\% response rate). The outcome was intent to lose weight with specific energy-balance related behaviors examined as predictor variables. A weighted logistic regression model was employed to examine the associations between sedentary behaviors, physical activity, and dietary-related variables with weight loss intent controlling for age, sex, BMI percentile, and race/ethnicity.

Results: Variables associating with adolescent intent to lose weight included 3 or more hours of video game playing ( $\mathrm{OR}=1.15,95 \% \mathrm{Cl}: 1.01-1.31, p=0.028)$, achieving $60 \mathrm{~min}$ of physical activity daily (OR $=0.66,95 \% \mathrm{Cl}: 0.59-$ $0.73, p<0.001)$, daily breakfast consumption $(\mathrm{OR}=0.76,95 \% \mathrm{Cl}: 0.67-0.87, p<0.001)$ and weekly salad consumption $(\mathrm{OR}=1.30,95 \% \mathrm{Cl}: 1.12-1.52, p=0.001)$.

Conclusions: Meeting physical activity guidelines and regular breakfast consumption associated with lower odds of weight loss intent and video game playing and salad consumption associated with higher odds of weight loss intent in a representative sample of US adolescents. Therefore, there is a discordance between adolescent weight loss intent and the engagement in specific energy balance-related health behaviors, particularly physical activity.
\end{abstract}

Keywords: Diet, Energy balance, Physical activity, Weight loss, Survey

\section{Introduction}

Adolescent obesity is continuing to be a major public health problem, with a US obesity prevalence of $20.6 \%$, adolescents are at risk for poor health [1,2]. Many nations throughout the world have identified youth overweight and obesity as not only a health issue but also an economic issue because of the high health care costs accompanying excess body weight $[3,4]$. Overweight and obesity are commonly defined as an excess of body fatness that

Correspondence: ryan.d.burns@utah.edu

Department of Health, Kinesiology, and Recreation, University of Utah, 1850 East 250 South Room 251, Salt Lake City, UT 84112, USA compromises health and daily function [5]. Although not without limitations at the individual level, Body Mass Index (BMI), a ratio of weight (in kilograms) to height squared (in meters), commonly serves as a screening measure for overweight and obesity in both youth and adults [6]. Excess body weight is thought to be primarily a function of positive energy-balance where total energy (kilocalories) consumed is consistently higher than total energy expended; thus, energy balance-related health behaviors greatly influence overweight and obesity risk [7].

Numerous interventions have been derived to prevent overweight and obesity in the pediatric population [8]. It

(c) The Author(s). 2019 Open Access This article is distributed under the terms of the Creative Commons Attribution 4.0 International License (http://creativecommons.org/licenses/by/4.0/), which permits unrestricted use, distribution, and reproduction in any medium, provided you give appropriate credit to the original author(s) and the source, provide a link to the Creative Commons license, and indicate if changes were made. The Creative Commons Public Domain Dedication waiver (http://creativecommons.org/publicdomain/zero/1.0/) applies to the data made available in this article, unless otherwise stated. 
has been recommended that programs should focus on targeting three primary behaviors of energy balance: sedentary behaviors, physical activity, and diet [9]. It has been shown that multicomponent community-based interventions targeting change in multiple behaviors at various times throughout the day may be the most effective strategy to prevent overweight and obesity [10]. While many of these interventions focusing on overweight and obesity prevention has yielded effectiveness [11], treatment of overweight and obesity (i.e., weight loss) tends to be a more difficult outcome to improve. Indeed, it has been shown that initial observed weight loss during multidisciplinary obesity treatment trials tends to be unsustainable in morbidly obese adolescents [12].

Although there is potential for community-based multicomponent and multi-behavioral interventions for overweight and obesity treatment, it is unclear what specific energy balance health behaviors adolescents tend to engage in if they do have intent to lose weight. Meeting daily physical activity guidelines and reducing behaviors such as excessive sedentary video game playing and television watching in combination with the consumption of energy dense foods such as fruits and vegetables could improve the probability of healthy and sustainable weight loss. These health behaviors may track to adulthood where they may further have an impact of morbidity and mortality [13-15]. Examining these relationships concurrently will provide information whether there is a discordance between intent and engagement in specific behaviors and may provide important information to help derive effective and sustainable pediatric obesity treatment programming.

Data from the National Youth Risk Behavior Survey (YRBS) provides information using a representative sample of US adolescents that can be used to examine relationships between several sedentary behavior, physical activity, and dietary-related variables with weight loss intent [16]. The National YRBS also collects data regarding current perceived weight status, which may be an effect modifier in the aforementioned health behavior associations with weight loss intent. Previous research conducted by Fan and Jin [17] used propensity score matching to examine the relationship between perceived overweight status and weight loss intent and between perceived overweight status and various energy balance related outcomes using pooled YRBS data. The authors observed that adolescents who perceived themselves as overweight had a stronger intention to lose weight but that this perception did not transfer to better eating and exercise habits [17]. Although a number of potential confounding variables were controlled for in their analyses employing propensity score matching, the independent relationships between specific energy balance health behaviors and weight loss intent were not explored nor was the potential moderating effect of perceived weight status
[17]. The current study aims to address these gaps using recent 2017 YRBS data. Therefore, the purpose of this study was to examine the associations between specific sedentary behaviors, physical activity-related behaviors, and dietary behaviors with the intent to lose weight in a sample of adolescents from the 2017 US National YRBS. A secondary purpose was to examine these associations using a 2017 YRBS subpopulation of adolescents who selfdescribed themselves as being overweight to test for modifying effects.

\section{Methods \\ Participants}

Data were collected in 2017 and analyzed in the spring of 2019. A multi-stage cluster sampling procedure was used to obtain a representative sample of US adolescents. The target population consisted of public and private high schoolers from grades 9 through 12. A weighting factor was applied to each adolescent to adjust for nonresponse and the oversampling of Black and Hispanic adolescents. The final weights were scaled so that the weighted count of students was equal to the total sample size, and the weighted proportions of students in each grade matched population projections [18]. The National YRBS has been approved by CDC's Institutional Review Board.

All regular public and private school students in the 50 States and the District of Columbia were included in the sampling frame. Schools were systematically selected with probability proportional to enrollment using a random start. One hundred and ninety-two schools were sampled and 144 of the 192 sampled schools participated (75\% response rate). All classes in a required subject or all classes meeting during a particular period of the day were included in the sampling frame. Systematic equal probability sampling with a random start was used to select classes from each school. The number of sampled adolescents was 18,324 with 14,765 of the 18,324 sampled students submitting questionnaires with usable data (81\% response rate). The overall response rate (school response rate $\times$ student response rate) was $60 \%$ [16].

\section{Youth risk behavior survey procedures}

YRBS questionnaires were self-administered and adolescents recorded responses on a computer-scannable questionnaire booklet or answer sheet. Local procedures for obtaining parental permission were followed before administering YRBS at any school. Trained data collectors traveled to each participating school to administer the questionnaires. The data collectors read a standardized script to participating students explaining the YRBS to students. All procedures for the YRBS were designed to protect privacy, allowing anonymous and voluntary participation. Students completed the self-administered questionnaire during one class period and recorded responses 
directly on the computer-scannable booklet or answer sheet. When possible, the students' desks were spread throughout the classroom. Students who were absent during the YRBS had the option to complete the questionnaire at a later date. Most questions on the YRBS have shown to have a high degree of test-retest reliability with kappa $=61-100 \%$ [19].

\section{Data processing}

All variables were dichotomized and most were dichotomized in accordance to the methods used on the 2017 YRBS. The outcome variable was the response item Q69 on the National YRBS that asked "Which of the following are you trying to do about your weight?" The response for item Q69 was numerically recoded $1=$ lose weight and $0=$ not lose weight. Three sets of predictor variables were analyzed consisting of variables relating to sedentary behavior, physical activity, and diet. Two sedentary behavior variables consisted of response items that asked about television watching (Q80: recoded $1=3$ or more hours/ day, $0=2$ or less hours/day) and video game playing (Q81: recoded $1=3$ or more hours/day, $0=2$ or less hours/day). Three activity-related variables consisted of items asking about daily physical activity (Q79: $1=60 \mathrm{~min} /$ day, $0=$ less than $60 \mathrm{~min} /$ day), sports team participation (Q83: $1=1$ or more sports team in past 12 months, $0=$ no sports teams in past 12 months), and engagement in muscular strength exercises (Q95: $1=3$ or more days/week, $0=2$ or fewer days/week). The physical activity item (Q79) was alternatively dichotomized in accordance to the US physical activity recommendations for children and adolescents (i.e., 60 min of physical activity every day of the week). Finally, the dietary-related variables consisted of response items that asked about breakfast consumption (Q78: $1=$ everyday consumption, $0=$ not everyday consumption), fruit consumption (Q71: $1=1$ or more times in past week, $0=$ no consumption in past week), green salad consumption (Q72: $1=1$ or more times in past week, $0=$ no consumption in past week), potato consumption (Q73: $1=1$ or more times in past week, $0=$ no consumption in past week), carrot consumption (Q74: $1=1$ or more times in past week, $0=$ no consumption in past week), and other vegetable consumption (Q75: $1=1$ or more times in past week, $0=$ no consumption in past week). All dietary questions were used to determine healthy food intake.

\section{Statistical analysis}

A probability weight based on sex, race/ethnicity, and grade level was applied to each adolescent to adjust for school and student nonresponse and the oversampling of Black and Hispanic students. The complex survey design, including assigned stratum and primary sampling unit, was accounted for using STATA's "svyset" prefix command. Of the adolescents who had valid outcome variable scores (Q69), there was less than 10\% missing data for every predictor, therefore missing data were not imputed. Weighted analyses used the Taylor Series Linearization variance estimation. For all descriptive characteristics, unweighted and weighted prevalence statistics were reported. Additionally, raw counts and unweighted and weighted prevalence were also reported for the outcome and predictor variables. To examine the associations between sedentary behaviors, physical activity, and specific dietary behaviors with adolescent weight loss intent, weighted logistic regression models were employed. Predictors were entered into the models using block-wise entry. Model 1 consisted of all primary predictor variables and Model 2 consisted of the Model 1 and the potential confounding of age, sex, BMI percentile, and race/ethnicity. BMI percentile, based on CDC growth charts, was used to provide an interpretable BMI metric accounting for adolescent growth and development. Social-economic status was not controlled for because it was not collected on the 2017 National YRBS. Referent levels for all primary predictor variables were categories coded as 0 (see Data Processing). The referent for sex was females and the referent for race/ethnicity was White because this category had the highest prevalence. Subpopulation analyses were also conducted to determine if adolescents who described themselves as overweight $(\mathrm{Q} 88: 1=$ slightly or very overweight, $0=$ not overweight), significantly modified the observed associations. Subpopulation analyses were carried out using STATA's "subpop" command. Communication of the results consisted of reporting the unadjusted and adjusted odds ratios (ORs) with corresponding 95\% Confidence Intervals. All analyses had an alpha level of $p<0.05$ and were carried out using STATA v15.0 statistical software package (College Station, Texas, USA).

\section{Results}

Unweighted and weighted prevalence for all descriptive characteristics are reported in Table 1 and the unweighted and weighted prevalence for the outcome and predictor variables are reported in Table 2. A little less than one-half $(47.3 \%)$ of the sample self-reported a current intention to lose weight and a little less than one-third of the sample self-described themselves as being either a little or very overweight (31.3\%). Results from the weighted logistic regression models using the total sample are reported in Table 3. After adjusting for age, sex, BMI percentile, and race/ethnicity, the energy balance-related behaviors that associated with higher odds of weight loss intent included playing video games for 3 or more hours per day $(p=$ $0.028)$ and regular salad consumption $(p=0.001)$. Health behaviors associating with lower odds of weight loss intent included meeting daily physical activity guidelines $(p<$ $0.001)$ and daily breakfast consumption $(p<0.001)$. Being male significantly related to lower odds of weight loss intent 
Table 1 Unweighted and weighted prevalence of observed descriptive characteristics

\begin{tabular}{|c|c|c|c|c|}
\hline Variable & Level & Unweighted Count & Unweighted Percent & Weighted Percent \\
\hline \multirow[t]{2}{*}{ Sex } & Females & 7526 & $51.4 \%$ & $50.7 \%$ \\
\hline & Males & 7112 & $48.6 \%$ & $49.3 \%$ \\
\hline \multirow[t]{7}{*}{ Age } & 12 years old or younger & 59 & $0.4 \%$ & $0.3 \%$ \\
\hline & 13 years old & 22 & $0.2 \%$ & $0.1 \%$ \\
\hline & 14 years old & 1922 & $13.1 \%$ & $11.7 \%$ \\
\hline & 15 years old & 3586 & $24.4 \%$ & $24.5 \%$ \\
\hline & 16 years old & 3688 & $25.1 \%$ & $25.4 \%$ \\
\hline & 17 years old & 3611 & $24.6 \%$ & $24.2 \%$ \\
\hline & 18 years old & 1796 & $12.2 \%$ & $13.4 \%$ \\
\hline \multirow[t]{8}{*}{ Race/Ethnicity } & White & 6261 & $44.4 \%$ & $53.5 \%$ \\
\hline & Asian & 648 & $4.5 \%$ & $3.5 \%$ \\
\hline & Black/African American & 2796 & $19.4 \%$ & $13.4 \%$ \\
\hline & Pacific Islander & 116 & $0.8 \%$ & $0.8 \%$ \\
\hline & American Indian/Alaskan Native & 137 & $1.0 \%$ & $0.5 \%$ \\
\hline & Hispanic/Latino & 1543 & $10.7 \%$ & $9.8 \%$ \\
\hline & Multiple-Hispanic/Latino & 2104 & $14.6 \%$ & $13.1 \%$ \\
\hline & Multiple-Non-Hispanic/Latino & 823 & $5.7 \%$ & $5.5 \%$ \\
\hline
\end{tabular}

A weighting factor was applied to each adolescent to adjust for nonresponse and the oversampling of Black and Hispanic adolescents

$(p<0.001)$ and higher BMI percentile related to higher odds of weight loss intent $(p<0.001)$. Regarding the race/ ethnicity covariate, compared to Whites, being Asian ( $p=$ $0.003)$ or single Hispanic/Latino $(p=0.001)$ or multiple Hispanic Latino $(p=0.028)$ associated with higher odds of weight loss intent while being Black associated with lower odds of weight loss intent $(p<0.001)$.

Results from the weighted logistic regression model using a subpopulation of adolescents who consider themselves either a little or very overweight are reported in Table 4. The observed associations using the self-perceived overweight sample included the association between meeting daily physical activity guidelines and lower odds of weight loss intent $(p<0.001)$. However, in contrast to the total sample, daily breakfast consumption $(p=0.564)$ and regular green salad consumption $(p=$ 0.559 ) did not significantly associate with weight loss intent in self-perceived overweight adolescents. Additionally, unlike using the total sample, muscular strength exercising at least 3 days per week significantly associated with higher odds of weight loss intent in self-perceived overweight adolescents $(p=0.022)$ and there was also an association between regular fruit consumption and higher odds of weight loss intent $(p=0.012)$.

\section{Discussion}

The purpose of this study was to examine the associations between specific sedentary behavior, physical activity, and dietary-related variables with adolescent weight loss intent using information collected on the 2017 US
National YRBS. The results indicated that meeting daily physical activity and daily breakfast consumption associated with lower odds of weight loss intent and that playing video games for 3 or more hours per day and regular salad consumption associated with higher odds of weight loss intent. Adolescents who perceived themselves as overweight slightly modified these results as only meeting daily physical activity guidelines associated with lower odds of weight loss intent and muscular strength training and fruit consumption associated with higher odds of weight loss intent. Although several significant associations were observed, no causal relationships can be established because of the cross-sectional design. A discussion of these findings and implications for public health practice are discussed further.

The salient findings were that specific energy balancerelated behaviors significantly associated with weight loss intent. Specifically, meeting daily physical activity guidelines and daily breakfast consumption associated with lower odds of weight loss intent and playing video games for 3 or more hours per day and regular salad consumption associated with higher odds of weight loss intent. The findings suggest that favorable associations between the engagement in health behaviors and weight loss intent were mixed. The associations between physical activity and breakfast consumption with lower odds of weight loss intent and the association between video game playing and higher odds of weight loss intent may compromise healthy and sustainable weight loss while the association between salad consumption and higher 
Table 2 Unweighted and weighted prevalence of observed predictor and outcome variables

\begin{tabular}{|c|c|c|c|c|}
\hline Variable & Level & Unweighted Count & Unweighted Percent & Weighted Percent \\
\hline \multirow[t]{2}{*}{ Weight Loss Intent } & Not intending to lose weight & 6079 & $52.7 \%$ & $52.9 \%$ \\
\hline & Intending to lose weight & 5462 & $47.3 \%$ & $47.1 \%$ \\
\hline \multirow[t]{2}{*}{ Weight Self-Perception } & Not perceived as overweight & 9605 & $68.7 \%$ & $68.5 \%$ \\
\hline & Perceived as overweight & 4381 & $31.3 \%$ & $31.5 \%$ \\
\hline \multirow[t]{2}{*}{ Television Watching } & Less than $3 \mathrm{~h}$ of television/day & 10,790 & $77.8 \%$ & $79.3 \%$ \\
\hline & 3 or more hours of television/day & 3077 & $22.2 \%$ & $20.7 \%$ \\
\hline \multirow[t]{2}{*}{ Video Games } & Less than $3 \mathrm{~h}$ of video game playing/day & 7855 & $56.8 \%$ & $57.0 \%$ \\
\hline & 3 or more hours of video game playing/day & 5984 & $43.2 \%$ & $43.0 \%$ \\
\hline \multirow[t]{2}{*}{ Physical Activity (PA) } & Less than 60 min of PA/day & 10,796 & $75.8 \%$ & $73.9 \%$ \\
\hline & 60 min of PA/day & 3442 & $24.2 \%$ & $26.1 \%$ \\
\hline \multirow[t]{2}{*}{ Sports Participation } & No sports teams & 5307 & $45.3 \%$ & $45.7 \%$ \\
\hline & At least 1 sports team & 6413 & $54.7 \%$ & $54.3 \%$ \\
\hline \multirow[t]{2}{*}{ Muscular Strength Exercising } & Less than 3 days of strength exercising & 5389 & $50.3 \%$ & $48.9 \%$ \\
\hline & 3 or more days of strength exercising & 5324 & $39.7 \%$ & $51.1 \%$ \\
\hline \multirow[t]{2}{*}{ Breakfast Consumption } & Do not consume breakfast everyday & 7783 & $65.3 \%$ & $64.7 \%$ \\
\hline & Consume breakfast everyday & 4135 & $34.7 \%$ & $35.3 \%$ \\
\hline \multirow[t]{2}{*}{ Consume Fruit } & Do not consume fruit & 1758 & $12.2 \%$ & $11.1 \%$ \\
\hline & Consume fruit at least once per week & 12,631 & $87.8 \%$ & $88.9 \%$ \\
\hline \multirow[t]{2}{*}{ Consume Salad } & Do not consume salad & 5972 & $42.6 \%$ & $40.7 \%$ \\
\hline & Consume salad at least once per week & 8053 & $57.4 \%$ & $59.3 \%$ \\
\hline \multirow[t]{2}{*}{ Consume Potatoes } & Do not consume potatoes & 5155 & $36.8 \%$ & $34.6 \%$ \\
\hline & Consume potatoes at least once per week & 8872 & $63.2 \%$ & $65.4 \%$ \\
\hline \multirow[t]{2}{*}{ Consume Carrots } & Do not consume carrots & 7890 & $56.4 \%$ & $54.7 \%$ \\
\hline & Consume carrots at least once per week & 6099 & $43.6 \%$ & $45.3 \%$ \\
\hline \multirow[t]{2}{*}{ Consume Other Vegetables } & Do not consume other vegetables & 2720 & $19.5 \%$ & $18.5 \%$ \\
\hline & Consume other vegetables at least once per week & 11,215 & $80.5 \%$ & $81.5 \%$ \\
\hline
\end{tabular}

PA stands for physical activity; a weighting factor was applied to each adolescent to adjust for nonresponse and the oversampling of Black and Hispanic adolescents

odds of weight loss intent may facilitate healthy weight loss efforts. Therefore, there is a discordance between weight loss intent and the engagement in some energybalance-related health behaviors. The recommendation for US children and adolescents for physical activity is 60 min of physical activity every day [20]. It has been shown that the addition of physical activity to diet programs may promote more sustainable weight loss compared to diet alone [21-23]. Although diet by itself may yield significant weight loss, especially in the morbidly obese, lower levels of sedentary behavior and higher levels of physical activity may supplement and may help sustain positive effects [24]. This, in addition to the other positive benefits of low sedentary behavior and higher habitual physical activity such as improved cognitive functioning, improved emotional wellbeing, improved health-related fitness, and a decrease in non-communicable disease risk needs to be communicated effectively to adolescents who intend to lose weight [25-27].
The findings also revealed that daily breakfast consumption associated with lower odds of weight loss intent. The influence of breakfast consumption on daily energy intake and overall health is debatable [28]. Refraining from consuming breakfast may yield an overall negative daily energy balance, which may lead to weight loss $[29,30]$. However, longitudinal observational studies have found that women who consume breakfast everyday were less likely to become obese those women who did not [31] and eating breakfast at home has been associated with the prevention of weight regaining after dieting [32]. Furthermore, consuming breakfast has also been correlated with higher levels of cognitive functioning and academic achievement in adolescents [33, 34]. Therefore, not eating breakfast everyday may not be a favorable health behavior in terms of cognitive functioning or for performance in academic classes but yet may yield negative energy balances for weight loss. Youth seeking to lose weight should be properly educated on the benefits and limitations of 
Table 3 Parameter estimates from the weighted multiple logistic regression model using the total sample

\begin{tabular}{|c|c|c|c|c|}
\hline & \multicolumn{2}{|c|}{ Model 1} & \multicolumn{2}{|c|}{ Model 2} \\
\hline & $\mathrm{OR}$ & $95 \% \mathrm{Cl}$ & $\mathrm{OR}$ & $95 \% \mathrm{Cl}$ \\
\hline \multicolumn{5}{|l|}{ Sedentary Behaviors } \\
\hline 3 or More Hours of Television/Day & 1.07 & $0.97-1.20$ & 1.03 & $0.92-1.18$ \\
\hline 3 or More Hours of Video Game Playing/Day & 1.07 & $0.95-1.21$ & $1.15^{\dagger}$ & $1.01-1.31$ \\
\hline \multicolumn{5}{|l|}{ Activity-Related Behaviors } \\
\hline $60 \mathrm{~min}$ of PA/Day & $0.57^{+}$ & $0.51-0.63$ & $0.66^{\dagger}$ & $0.59-0.73$ \\
\hline At least 1 Sports Team & $0.84^{\dagger}$ & $0.76-0.94$ & 0.88 & $0.76-1.00$ \\
\hline 3 or More Days of Strength Exercising & 0.90 & $0.80-1.01$ & 1.03 & $0.92-1.16$ \\
\hline \multicolumn{5}{|l|}{ Dietary Behaviors } \\
\hline Consume Breakfast Everyday & $0.61^{\dagger}$ & $0.55-0.69$ & $0.76^{\dagger}$ & $0.67-0.87$ \\
\hline Consume Fruit & $1.47^{\dagger}$ & $1.22-1.77$ & 1.26 & $0.99-1.61$ \\
\hline Consume Salad & $1.43^{\dagger}$ & $1.30-1.58$ & $1.30^{\dagger}$ & $1.12-1.52$ \\
\hline Consume Potatoes & 0.90 & $0.83-1.04$ & 0.90 & $0.80-1.00$ \\
\hline Consume Carrots & 0.93 & $0.82-1.04$ & 0.93 & $0.82-1.07$ \\
\hline Consume Other Vegetables & $1.14^{\dagger}$ & $1.02-1.25$ & 0.99 & $0.84-1.17$ \\
\hline Age (years) & & & 0.99 & $0.96-1.03$ \\
\hline Male & & & $0.26^{\dagger}$ & $0.23-0.31$ \\
\hline BMI \% & & & $1.05^{\dagger}$ & $1.04-1.05$ \\
\hline American Indian/Alaskan Native & & & 0.75 & $0.45-1.25$ \\
\hline Asian & & & $1.70^{\dagger}$ & $1.20-2.41$ \\
\hline Black/African American & & & $0.56^{\dagger}$ & $0.45-0.70$ \\
\hline Pacific Islander & & & 0.66 & $0.34-1.28$ \\
\hline Hispanic/Latino & & & $1.45^{\dagger}$ & $1.17-1.79$ \\
\hline Multiple-Hispanic/Latino & & & $1.21^{\dagger}$ & $1.02-1.45$ \\
\hline Multiple-Non-Hispanic/Latino & & & 1.12 & $0.89-1.42$ \\
\hline
\end{tabular}

Outcome is intending to lose body weight; OR stands from Odds Ratio; $95 \% \mathrm{Cl}$ stands for $95 \%$ Confidence Interval; PA is physical activity; BMI\% is Body Mass Index age and sex percentile; referent for sex is female; referent for race/ethnicity is White; Model $1=$ sedentary, physical activity, and dietary-related predictors; Model $2=$ Model $1+$ potential confounding, $p<0.05$

bold and + indicates statistical significance, $p<0.05$

breakfast consumption and how consuming breakfast may facilitate consumption of a healthy diet [35].

Results of the secondary analysis revealed that in a subpopulation of adolescents who describe themselves as overweight, there was some modified associations compared to those observed using the total 2017 YRBS sample. The lone health behavior predictor associated with lower odds of weight loss intent in the subpopulation sample was meeting daily physical activity guidelines. However, unlike the total sample, the muscular strength exercising at least 3 days per week associated with higher odds of weight loss intent. It has been shown that youth with obesity tend to have impaired muscular fitness compared to normal weight peers [36]. Therefore, the relationship between muscular strength exercising and weight loss intent in perceived overweight adolescents is an encouraging finding [37]. Muscular strength training may improve motor skills, lower injury rates, and improve self-esteem and interest in fitness
[38]. However, its direct role in weight loss is not as established but may still improve certain health and psychosocial parameters in obese youth $[39,40]$. Interventions have shown that using a combination of both aerobic and resistance (muscular strength) training yielded greater reductions in body weight and greater improvements in body fat and cardiorespiratory fitness compared to control and resistance training only groups [41]. A message to incorporate aerobic exercise to manifest negative energy balance is also needed however, despite participation in muscular strength training programs. The only other predictor associating with higher odds of weight loss intent in the subpopulation analysis was regular fruit consumption. Although this is a positive finding given the health benefits of fruit consumption, there were no other favorable associations found between regular vegetable consumption with weight loss intent. The literature yields mixed findings whether fruit or vegetable consumption alone or in combination yields weight loss or 
Table 4 Parameter estimates from the weighted multiple logistic regression model using a subpopulation of adolescents who described themselves as either slightly or very overweight

\begin{tabular}{|c|c|c|c|c|}
\hline & \multicolumn{2}{|c|}{ Model 1} & \multicolumn{2}{|c|}{ Model 2} \\
\hline & $\overline{O R}$ & $95 \% \mathrm{Cl}$ & $\mathrm{OR}$ & $95 \% \mathrm{Cl}$ \\
\hline \multicolumn{5}{|l|}{ Sedentary Behaviors } \\
\hline 3 or More Hours of Television/Day & 0.87 & $0.67-1.12$ & 0.97 & $0.72-1.30$ \\
\hline 3 or More Hours of Video Game Playing/Day & 0.85 & $0.67-1.05$ & 0.93 & $0.74-1.18$ \\
\hline \multicolumn{5}{|l|}{ Activity-Related Behaviors } \\
\hline 60 min of PA/Day & $0.57^{+}$ & $0.38-0.81$ & $0.65^{\dagger}$ & $0.45-0.94$ \\
\hline At least 1 Sports Team & 0.92 & $0.70-1.21$ & 0.99 & $0.73-1.32$ \\
\hline 3 or More Days of Strength Exercising & $1.31^{\dagger}$ & $1.02-1.69$ & $1.45^{\dagger}$ & $1.06-2.00$ \\
\hline \multicolumn{5}{|l|}{ Dietary Behaviors } \\
\hline Consume Breakfast Everyday & 0.86 & $0.64-1.09$ & 0.92 & $0.70-1.22$ \\
\hline Consume Fruit & $1.89^{\dagger}$ & $1.33-2.70$ & $1.60^{\dagger}$ & $1.12-2.37$ \\
\hline Consume Salad & 1.19 & $0.89-1.59$ & 1.11 & $0.80-1.54$ \\
\hline Consume Potatoes & $0.71^{\dagger}$ & $0.53-0.97$ & 0.73 & $0.52-1.01$ \\
\hline Consume Carrots & 1.10 & $0.83-1.46$ & 1.19 & $0.87-1.62$ \\
\hline Consume Other Vegetables & 1.34 & $0.88-2.03$ & 1.13 & $0.71-1.76$ \\
\hline Age (years) & & & 0.93 & $0.83-1.05$ \\
\hline Male & & & $0.44^{\dagger}$ & $0.32-0.61$ \\
\hline BMI \% & & & 1.00 & $0.99-1.01$ \\
\hline American Indian/Alaskan Native & & & 0.76 & $0.22-2.68$ \\
\hline Asian & & & 1.28 & $0.64-2.59$ \\
\hline Black/African American & & & 1.18 & $0.74-1.89$ \\
\hline Pacific Islander & & & 3.77 & $0.55-26.0$ \\
\hline Hispanic/Latino & & & $2.13^{\dagger}$ & $1.17-3.89$ \\
\hline Multiple-Hispanic/Latino & & & $1.62^{\dagger}$ & $1.03-2.51$ \\
\hline Multiple-Non-Hispanic/Latino & & & 1.34 & $0.69-2.62$ \\
\hline
\end{tabular}

Outcome is intending to lose body weight; OR stands from Odds Ratio; $95 \% \mathrm{Cl}$ stands for $95 \%$ Confidence Interval; PA is physical activity; BMI\% is Body Mass Index age and sex percentile; referent for sex is female; referent for race/ethnicity is White; Model $1=$ sedentary, physical activity, and dietary-related predictors; Model $2=$ Model $1+$ potential confounding, $p<0.05$

bold and + indicates statistical significance, $p<0.05$

attenuated weight gain in children independent of other energy balance-related health behaviors, yet encouraging regular consumption of fruit and vegetables in adolescents is still recommended for overall health [42].

The results of this study show a discordance in the associations between weight loss intent and the engagement in specific energy balance-related health behaviors. Using 2010 YRBS data, Kakinami et al. [43] also found that weight loss attempts alone do not affect the likelihood of meeting recommendations for diet and physical activity. This potentially suggests that adolescents who intend to lose weight do not know how or what specific health behaviors to engage in to yield a negative energy balance, particularly with regards to sedentary behavior and physical activity. The specific relationships that support this conjecture in the current study was the association between video game playing for 3 or more hours per day and higher odds of weight loss intent and the association between meeting daily physical activity guidelines and higher odds of weight loss intent. Although diet has been shown to be a major factor in creating a negative energy balance, physical activity has at least a supporting role and provides numerous other benefits independent of dietary behaviors [44]. Current recommendations are that both diet and physical activity need to be engaged in to yield efficient and sustainable negative energy balance that leads to weight loss $[45,46]$. The role of physical activity may be especially important during adolescence as a longitudinal study found that resting energy expenditure dramatically decreases during puberty [47]. These messages could be more effectively communicated to youth trying to lose weight as meeting daily physical activity guidelines and reducing behaviors such as excessive sedentary video game playing in combination with the consumption of energy dense foods such as fruits and vegetables could improve the probability of healthy and sustainable weight loss. 
Strengths of this study include the use of a large and national representative sample of US adolescents and the use of multiple sedentary behavior, physical activity, and dietary variables to associate with weight loss intent. There are also limitations to this study that must be considered. First, the study design was cross-sectional, therefore no causal inferences can be made; follow-up studies need to employ longitudinal research designs. Along these lines, the direction of association was most likely intent leading to engagement in health behaviors, however the study design also precludes examination of the directionality of association. Future research should employ longitudinal research designs using weight loss intent as the predictor and specific energy-balance-related health behaviors as outcomes. Second, all variables were collected using self-report, therefore there is potential for recall and social desirability bias. Third, only one subpopulation of the National YRBS was examined to test for effect modification (overweight perception), future research should examine the relationships with other variables which may contribute to effect modification. Finally, psychosocial mediators such as perceived social support and self-efficacy may play a role in the engagement in health behaviors. These variables were not collected and may have confounded the association between health behaviors and weight loss intent.

\section{Conclusion}

In conclusion, meeting daily physical activity guidelines and daily breakfast consumption associated with lower odds of weight loss intent and 3 or more hours of video game playing and regular salad consumption associated with higher odds of weight loss intent in a representative sample of adolescents from the 2017 US National YRBS. Adolescents who perceived themselves as overweight slightly modified these results. These results indicate that there is a gap between intent to lose weight and engagement in specific energy balance-related health behaviors. This is especially true for physical activity as the association between meeting daily physical activity guidelines and lower odds with weight loss intent was robust and also held within the perceived overweight subpopulation. It appears that adolescents who regularly consume salads associate with higher odds of weight loss intent however regular breakfast consumption related to lower odds of weight loss intent. Although consumption of breakfast contributes to positive energy balance, skipping breakfast has been shown to associate with a higher risk of weight regain and may also compromise cognitive functioning. These results indicate that adolescents who intend to lose weight should be aware of current health behaviors and how engagement in these health behaviors contribute to energy balance and to overall health.

\section{Abbreviations}

BMI: Body Mass Index; CDC: Centers for Disease Control and Prevention; Cl: Confidence Interval; OR: Odds Ratio; YRBS: Youth Risk Behavior Survey

\section{Acknowledgements}

The author would like to thank the adolescents who participated in this study.

\section{Author's contributions}

RB conceptualized the study, performed the data analyses, wrote the initial draft of the manuscript, and read and approved the final manuscript.

\section{Funding}

No funding was obtained.

\section{Availability of data and materials}

The datasets analyzed during the current study are available in the CDC National YRBS website, https://www.cdc.gov/healthyyouth/data/yrbs/data. htm.

\section{Ethics approval and consent to participate}

All participants provided written consent. The National YRBS was approved by the CDC Institutional Review Board (\#1969.0).

\section{Consent for publication}

Not applicable.

\section{Competing interests}

Ryan D. Burns is an Associate Editor of the Energy Balance-Related Behaviour section of BMC Public Health.

Received: 19 June 2019 Accepted: 28 August 2019

Published online: 02 September 2019

\section{References}

1. Hales CM, Carroll MD, Fryar CD, Ogden CL. Prevalence of obesity among adults and youth: United States, 2015-2016. NCHS Data Brief. 2017;288:1-8.

2. Ogden $\mathrm{CL}$, Carroll MD, Fakhouri TH, et al. Prevalence of obesity among youths by household income and education level of head of household United States 2011-2014. MMWR Morb Mortal Wkly Rep. 2018;67(6):186-9.

3. Hammond RA, Levine R. The economic impact of obesity in the United States. Diabetes Metab Syndr Obes. 2010;3:285-95.

4. James WPT, McPherson K. The costs of overweight. Lancet Public Health. 2017;2(5):e203-4.

5. Hubbard VS. Defining overweight and obesity: what are the issues? Am J Clin Nutr. 2000;72(5):1067-8.

6. Kuczmarski RJ, Flegal KM. Criteria for definition of overweight in transition: background and recommendations for the United States. Am J Clin Nutr. 2000;72(5):1074-81.

7. $\mathrm{Ng} \mathrm{M}$, Fleming $\mathrm{T}$, Robinson $\mathrm{M}$, et al. Global, regional and national prevalence of overweight and obesity in children and adults 1980-2013: a systematic analysis. Lancet. 2014;384(9945):766-81.

8. Karacabeyli D, Allender S, Pinkney S, Amed S. Evaluation of complex community-based childhood obesity prevention interventions. Obes Rev. 2018;19(8):1080-92.

9. Committee on Accelerating Progress in Obesity Prevention, Food and Nutrition Board; Institute of Medicine. In: Glickman D, Parker L, Sim L, et al., editors. Accelerating progress in obesity prevention: solving the weight of the nation. Washington (DC): National Academies Press; 2012.

10. Weihrauch-Bluher S, Kromeyer-Hauschild K, Graf C, et al. Current guidelines for obesity prevention in childhood and adolescence. Obes Facts. 2018;11(3):263-76.

11. Verstraeten $R$, Roberfroid $D$, Lachat $C$, et al. Effectiveness of preventive school-based obesity interventions in low- and middle-income countries: a systematic review. Am J Clin Nutr. 2012;96(2):415-38.

12. Zolotarjova J, ten Velde G, Vreugdenhil ACE. Effects of multidisciplinary interventions on weight loss and heath outcomes in children and adolescents with morbid obesity. Obes Rev. 2018;19(7):931-46.

13. McVeigh J, Smith A, Howie E, Straker L. Trajectories of television watching from childhood to early adulthood and their association with body 
composition and mental health outcomes in young adults. PLoS One. 2016; 11(4):e0152879. https://doi.org/10.1371/journal.pone.0152879.

14. Hayes G, Dowd KP, MacDonncha C, Donnelly AE. Tracking of physical activity and sedentary behavior from adolescence to young adulthood: a systematic literature review. J Adolesc Health. 2019. https://doi.org/10.1016/j. jadohealth.2019.03.013.

15. Schneider BC, Dumith Sde C, Lopes C, Severo M, Assuncao MC. How do tracking and changes in dietary pattern during adolescence relate to the amount of body fat in early adulthood? PLoS One. 2016;11(2):e0149299. https://doi.org/10.1371/journal.pone.0149299.

16. Centers for Disease Control and Prevention. 2017 Youth Risk Behavior Survey Data. Available at: www.cdc.gov/yrbs. Accessed 02 Jan 2019

17. Fan M, Jin Y. The effects of weight perception on adolescents' weight-loss intention and behaviors: evidence from the youth risk behavior surveillance survey. Int J Environ Res Public Health. 2015;12(11):14640-68.

18. Centers for Disease Control and Prevention. Methodology of the youth risk behavior surveillance system-2013. MMWR Recomm Rep. 2013;62(RR-1):1-20.

19. Brener ND, Colluns JL, Kann L, et al. Reliability of the youth risk behavior survey questionnaire. Am J Epidemiol. 1995;141(6):575-80.

20. US Department of Health and Human Services. Physical activity guidelines for Americans. 2nd ed. Washington, DC: US Department of Health and Human Services; 2018.

21. Field AE, Haines J, Rosner B, Willet WC. Weight-control behaviors and subsequent weight change among adolescents and young adult females. Am J Clin Nutr. 2010;91(1):147-53.

22. Jakicic JM. The effect of physical activity on body weight. Obesity (Silver Spring). 2009;17(S3):S34-8.

23. Foster-Schubert KE, Alfano CM, Duggan CR, et al. Effect of diet and exercise, alone or combined, on weight and body composition in overweight-toobese post-menopausal women. Obesity (Silver Spring). 2012;20(8):1628-38.

24. Kelly AS, Barlow SE, Rao G, et al. Severe obesity in children and adolescents: identification, associated health risks, and treatment approaches: a scientific statement from the American Heart Association. Circulation. 2013;128(15):1689-712.

25. Boreham C, Riddoch C. The physical activity, fitness, and health of children. J Sports Sci. 2001;19(12):915-9.

26. Trudeau F, Shephard RJ. Physical education, school physical activity, schoo sports and academic performance. Int J Behav Nutr Phys Act. 2008;5(10). https://doi.org/10.1186/1479-5868-5-10.

27. Yli-Piipari S, Wang CK, Jaakkola T, et al. Examining the growth trajectories of physical education students' motivation, enjoyment, and physical activity: a person-oriented approach. J Appl Sport Psychol. 2012;24(4):401-17.

28. Bohan Brown MM. Digging into breakfast; serving up a better understanding of the effects on health of the "most important meal of the day". Am J Clin Nutr. 2019. https://doi.org/10.1093/ajcn/nqz068.

29. Sievert K, Hussain SM, Page MJ, et al. Effect of breakfast on weight and energy intake: systematic review and meta-analysis of randomised controlled trials. BMJ. 2019;364:142. https://doi.org/10.1136/bmj.142.

30. Levitsky DA, Pacanowski CR. Effect of skipping breakfast on subsequent energy intake. Physiol Behav. 2013;119:9-16.

31. Guinter MA, Park YM, Steck SE, Sandler DP. Day-to-day regularity in breakfast consumption is associated with weight status in a prospective cohort of women. Int J Obes. https://doi.org/10.1038/s41366-019-0356-6.

32. Brikou D, Zannidi D, Karfopoulou E, et al. Breakfast consumption and weight-loss maintenance: results from the MedWeight study. Br J Nutr. 2016:115(12):2246-51.

33. Tan Z, Zhang N, Liu A, et al. The effects of breakfast on short-term cognitive function among Chinese white-collar workers: protocol for a three-phase crossover study. BMC Public Health. 2017;17:92. https:/doi.org/10.1186/s12889-017-4017-1.

34. Burns RD, Fu Y, Brusseau TA, et al. Relationships among physical activity, sleep duration, diet, and academic achievement in a sample of adolescents. Prev Med Rep. 2018;12:71-4.

35. Ramsey SA, Bloch TD, Marriage B, et al. Skipping breakfast is associated with lower diet quality in young US children. Eur J Clin Nutr. 2018;72(4):548-56.

36. Smith JJ, Eather N, Morgan PJ, et al. The health benefits of muscular fitness for children and adolescents: a systematic review and meta-analysis. Sports Med. 2014;44(9):1209-43.

37. Thivel $D$, Ring-Dimitriou $S$, Weghuber $D$, et al. Muscle strength and fitness in pediatric obesity: a systematic review from the European childhood obesity group. Obes Facts. 2016;9(1):52-63.

38. Myers AM, Beam NW, Fakhoury JD. Resistance training for children and adolescents. Transl Pediatr. 2017;6(3):137-43.
39. Ten Hoor GA, Plasqui G, Ruiter RAC, et al. A new direction in psychology and health: resistance exercise training for obese children and adolescents. Psychol Health. 2016;31(1):1-8,

40. Garcia-Hermoso A, Ramirez-Velez R, Ramierz-Campillo R, et al. Concurrent aerobic plus resistance exercise versus aerobic exercise alone to improve health outcomes in paediatric obesity: a systematic review and metaanalysis. Br J Sports Med. 2018;52(3):161-6.

41. Ho SS, Dhaliwal SS, Hills AP, Pai S. The effect of 12 weeks of aerobic, resistance or combination exercise training on cardiovascular risk factors in the overweight and obese in a randomized trial. BMC Public Health. 2012; 12:704. https://doi.org/10.1186/1471-2458-12-704.

42. Ledoux TA, Hingle MD, Baranowski T. Relationship of fruit and vegetable intake with adiposity: a systematic review. Obes Rev. 2011;12(50):e143-50.

43. Kakinami L, Houle-Jonson SA, Demissie Z, et al. Meeting fruit and vegetable consumption and physical activity recommendations among adolescents intending to lose weight. Prev Med Rep. 2019;13:11-5.

44. Swift DL, Jojannsen NM, Lavie CJ, et al. The role of exercise and physical activity in weight loss and maintenance. Prog Cardiovasc Dis. 2014;56(4):441-7.

45. Butryn ML, Wadden TA, Rukstalis MR, et al. Maintenance of weight loss in adolescents: current status and future directions. J Obes. 2010;2010:789280.

46. Goldberg JH, King AC. Physical activity and weight management across the lifespan. Annu Rev Public Health. 2007;28:145-70.

47. Mostazir M, Jeffrey A, Hosking J, et al. Evidence for energy conservation during pubertal growth. A 1-year longitudinal study (EarlyBird 71). Int J Obes. 2016;40(11):1619-26.

\section{Publisher's Note}

Springer Nature remains neutral with regard to jurisdictional claims in published maps and institutional affiliations.
Ready to submit your research? Choose BMC and benefit from:

- fast, convenient online submission

- thorough peer review by experienced researchers in your field

- rapid publication on acceptance

- support for research data, including large and complex data types

- gold Open Access which fosters wider collaboration and increased citations

- maximum visibility for your research: over $100 \mathrm{M}$ website views per year

At $\mathrm{BMC}$, research is always in progress.

Learn more biomedcentral.com/submissions 